\title{
The Oral Health Status and Attitudes of Saudi Adolescent Male Students in Albaha Province
}

\author{
Abdullah Ali Alzahrani ${ }^{1 *}$, Eltayeb Mohammed Alhassan ${ }^{1}$ and Mohammad A Albanghali ${ }^{2}$ \\ ${ }^{1}$ Department of Dental Health, Faculty of Applied Medical Sciences, Albaha University, Saudi Arabia \\ ${ }^{2}$ Department of Public Health, Faculty of Applied Medical Science, Albaha University, Saudi Arabia.
}

Submission: November 15, 2018; Published: November 29, 2018

*Corresponding author: Abdullah Ali Alzahrani, Dental Health Department, Faculty of Applied Medical Sciences, Albaha University, Albaha, P.O. Box 18, Postal Code 65951, Saudi Arabia

\begin{abstract}
Objectives: To explore and examine the oral health status of Saudi adolescent male students aged 12-15 years in Albaha province and evaluating the oral health attitudes of this population.

Methods: This was a cross-sectional study in which random sampling was used. Data was collected at schools of the subjects between November 2017 and February 2018. A clinical examination was carried out to evaluate the presence of tooth decay, plaque and gingival bleeding. Then a face-to-face interviews with the study participants were employed to measure their oral health attitudes using a pre-designed questionnaire. SPSS $₫$ version 20.0 was used to conduct the data analysis.
\end{abstract}

Results: Two hundred and forty-nine Saudi adolescent male students from three different territories in Albaha province were recruited. The rate of dental caries, plaque and gingival bleeding was determined to be high (76\%, $94 \%$ and $86 \%$, respectively). A $73 \%$ of the adolescents were seen to hold a moderate attitude towards the preservation of their oral health. Only $40 \%$ of the participants visited the dentist regularly and just $16 \%$ of the children reported brushing their teeth twice daily.

Conclusion: The oral health status of the studied population was poor. Moderately positive oral health attitudes were demonstrated overall. Further research into the implementation of oral health-based educational and preventive strategies is urgently required to advance the oral health status and practices of Albaha province community members.

Keywords: Dental caries; Periodontology; Dental hygiene, Children; Knowledge; Attitudes; Oral health

Abbreviations: DMFT: Decayed Missed and Filled teeth Index; PI: Plaque Index; GI: Gingival Index; WHO: World Health Organization

\section{Introduction}

There is a burgeoning amount of global literature on the impact of poor oral health status on quality of life, particularly that pertaining to adolescents. For example, tooth decay affects the willingness of children to speak, smile and eat [1]. Likewise, the adverse effects of periodontal disease on the quality of life of individuals have been observed to be substantial [2]. Thus, an exploration and evaluation of the oral health status of any community is warranted to inform the establishment and implementation of suitable oral health interventions to reduce these negative effects.

The prevalence of dental caries among the Saudi population, particularly among adolescents, is relatively high [3]. Nationally, dental caries in Saudi children was estimated to be $80 \%$ and $70 \%$ for primary dentition and permanent dentition, respectively, with respective mean Decayed, Missing or Filled Teeth (DMFT) index scores of 5.0 and 3.5, as per the findings of a systematic review [4]. Meanwhile, an overall prevalence of $73 \%$ for dental caries was reported in a sample of 711 Saudi schoolchildren in Dammam [5]. Similarly, a mean DMFT index score of 3.27 was found for 48 children in Tabuk [6]. The incidence of dental caries was also determined to be $\geq 80 \%$ in 1844 schoolchildren in Riyadh [7]. Similarly, tooth decay was identified in $\geq 78 \%$ of adolescents ( $\mathrm{n}=724$ ) aged 12-14 years following a cross-sectional survey conducted in Jeddah [8].

Periodontal disease is regarded as one of the most common chronic illnesses worldwide. The association of periodontitis with several risk factors, including increased waist circumference, obesity, overweight and weight gain, is often used to explain the prevalence of periodontal disease [9]. The rate of plaque and gingivitis in Saudi children aged 7-15 years in Riyadh was reported to be $46 \%(n=93)$ in another study [10]. A high incidence of plaque was also identified in 500 adolescents based in Jazan following a cross-sectional survey, where the mean plaque index (PI) score for male and female schoolchildren was found to be 0.69 
and 0.66 , respectively [11]. Additionally, gingivitis was seen to be pervasive in Saudi adults aged $18-40$ years $(n=385,100 \%)$, with a mean gingival index (GI) score of $1.68 \pm 0.31$, indicating moderate gingival inflammation [12].

The health and well-being of individuals has been shown to be enhanced by positive attitudes to oral health [13], while the maintenance of sound oral hygiene habits and attitudes was found to have a strong association with healthy teeth and gums [14]. It was established that $33 \%$ of adolescents $(n=287)$ aged $15-18$ years did not brush their teeth following a cross-sectional survey conducted in Riyadh [15]. It was demonstrated in other research on 917 Saudi schoolchildren, that despite having satisfactory attitudes and knowledge of oral health, 59\% of them practiced poor oral hygiene [16].

However, despite an extensive evaluation of oral health in the different geographical areas of Saudi Arabia and in Saudi populations of varying ages, in which poor oral hygiene, habits and attitudes, and widespread dental caries and periodontal disease have been identified $[5,13]$, yet a little is known in this regard among adolescents in Albaha province, Saudi Arabia. Moreover, the association of impacts resulted from oral diseases with individuals' quality of life and well-being is well confirmed [17]. Thus, those two reasons may justify the importance of conducting the current study which aims to explore and examine the oral health status and attitudes of Saudi adolescent male students aged 12-15 years living in Albaha province.

\section{Methods}

\section{Settings and participants}

Three schools distributed across three different territories (Albaha, Alatawelah and Alaquiq) in Albaha province, Saudi Arabia, were randomly selected for inclusion in the study. Information sheets outlining the purpose of and methodology used in the research, and containing informed consent forms, were sent to the parents of students between September and October 2017, prior to conducting the study. The study subjects comprised Saudi adolescent male students aged 12-15 years. The participants were classified according to three different age groups; i.e., 12-13 years, 14 years and 15 years. They were interviewed to ascertain their attitudes to their oral health, and then underwent a clinical examination to assess for periodontal disease and dental caries to gauge their overall oral health status.

\section{Ethical considerations}

This study was approved by the Planning, Research and Studies Department at the Saudi Ministry of Education (Albaha branch) (approval reference number: 39195280). It can be confirmed that this study was conducted in accordance with ethical standards of the Saudi Ministry of Education and Albaha University. Parents of the participants were provided with written information sheets that outlined the objective and procedures to be used in the study. Informed written consent was obtained from the parents prior to conducting the study. The parents were reassured that all personal information would be kept confidential and were informed of the right to contribute and of the right to withdraw from the study without having to provide a reason why, and without prejudice, at any time.

\section{Sampling and data collection}

A randomized sampling technique was employed between November 2017 and February 2018 to select the study sample. The local education authority, the Albaha branch of the Saudi Ministry of Education, provided statistical information regarding the total number of students and details of schools in the region. One school was randomly chosen from each of the Albaha, Alatawelah and Alaquiq regions in Albaha province. The students were included in the study if their parents agreed that they could participate and if they provided informed written consent. However, female students were excluded from the study sample, mainly owing to cultural challenges in accessing this population at schools, particularly as the researchers were men. The sample size was calculated based on the total number of Saudi adolescent male students $(n=5479)$ aged $12-15$ years living and registered in Albaha province, using an adjusted 95\% confidence level. The sample size thought to have enough power and validity for the purpose of the study was consequently estimated to be 255 participants.

\section{Clinical examination}

The study participants were clinically examined at their schools for assessment of their periodontal and dental caries status. The PI and GI developed and published by the World Health Organization (WHO) [18] were used to assess gingival bleeding and perform a supragingival dental calculus evaluation of all teeth. The DMFT index, also established by the WHO [18] was employed to determine the significance of the dental decay. For quality reasons and based on the recommendations of the WHO [18], 10\% of the randomly selected cases (i.e., 26 adolescents) were re-examined by an independent examiner to measure intraexaminer consistency and agreement regarding the oral health status evaluation. Interrater reliability was measured using Cohen's kappa, and the values for dental caries, gingival bleeding and plaque were estimated to be $0.84,0.87$ and 0.91 respectively, demonstrating high consistency and agreement between the findings of the two examiners. The clinical examinations were performed under clinical conditions, using portable clinic lights and disposable examination kits, consisting of tweezers, sharp probes (number 4), a mouth mirror, cotton, gauze, a face mask, gloves, and CPI periodontal probes.

\section{A face-to-face interview on attitudes to oral health}

Prior to conducting the clinical examination, face-to-face interviews were conducted with the participants with a view to completing a pre-designed questionnaire on attitudes to oral health. The questionnaire was adapted from the Hiroshima University-Dental Behavioral Inventory [19], with minor 


\section{Advances in Dentistry \& Oral Health}

modifications to ensure cultural applicability. The final version included 15 items that focused on the attitudes of the participants to their oral health and their sociodemographic backgrounds (Table 1).

Table 1: The questionnaire administered to participants on their oral health attitude.

To ensure that the risk of bias was kept to a minimum and to avoid influencing the clinical examinations owing to prior knowledge of attitudes to oral health, the investigators were asked to record the clinical examination findings separate from the questionnaire results.

\begin{tabular}{|c|c|c|}
\hline Statement & Agree & Disagree \\
\hline I have visited my dentist and informed that I brush my teeth very well. & & \\
\hline I brush my teeth twice daily and have been taught how to use my brush professic & & \\
\hline I brush each one of my teeth carefully. & & \\
\hline I prefer to clean my teeth using a toothbrush and toothpaste rather than misw & & \\
\hline I use a child-sized toothbrush with hard bristles. & & \\
\hline I often check my teeth in the mirror after brushing them. & & \\
\hline I don't feel I have brushed my teeth well unless I use strong strokes. & & \\
\hline I use floss on a regular basis. & & \\
\hline I am worried about the colour and appearance of my teeth. & & \\
\hline I am concerned about the colour and appearance of my gums. & & \\
\hline My gums do not bleed when I brush my teeth. & & \\
\hline I regularly use mouthwash. & & \\
\hline I worry about having bad breath. & & \\
\hline Generally, I try to visit the dentist regularly, even if I don't have toothache. & & \\
\hline I have used dye to determine to what extent my teeth are clean. & & \\
\hline
\end{tabular}

\section{Statistical analysis}

The total number of statements reflective of a positive oral health attitude were added together to calculate the final score for attitudes to oral health based on the 15 items. The final score varied from $0-15$; with a poor attitude to oral health classified as a score of 1-5, a moderate attitude categorized as a score of 6-10 and a sound attitude graded as a score of 11-15. The DMFT index, the PI and the GI were stratified as low or high strata, based on the median for each index. Statistical Package for the Social Sciences ${ }^{\circledR}$ version 20.0 was used to analyze the data. The chi-square test was employed to investigate an association between the categorical variables. Fisher's exact test was utilized, as appropriate. The Kruskal-Wallis $\mathrm{H}$ test (a nonparametric [distribution free] test) was used to compare the medians from the different groups.

\section{Results}

\section{The sociodemographic characteristics of the partici- pants}

Two hundred and eighty Saudi male adolescent students aged 12-15 years were invited from three schools to participate in the study. Eighteen students were absent on the day of the clinical examination and 13 students decided against participating. Thus, 249 adolescents were finally included in the research (i.e., a response rate of $89 \%$ ). The sociodemographic characteristics of the participants were recorded according to their age and the geographical location of the school (Table 2).
Table 2: The sociodemographic characteristics of the participants according to age group and school region $(n=249)$.

\begin{tabular}{|c|c|c|}
\hline Variable & $\mathbf{n}$ & \% \\
\hline Age (years) & 110 & 44.2 \\
\hline Dec-(12-13) & 75 & 30.1 \\
\hline 14 & 64 & 25.7 \\
\hline 15 & 125 & 50.2 \\
\hline School region \\
\hline Alaquiq & 68 & 27.3 \\
\hline Alatawelah & 56 & 22.5 \\
\hline Albaha &
\end{tabular}

\section{Dental caries status}

The prevalence of dental caries in the studied population was considerably high. Of the 249 participants, tooth decay was identified in 189 (76\%) of them at the time of examination. Significantly, the DMFT values were observed to violate the normality assumption. The calculated mean for the DMFT value was $0.47 \pm 0.58$. The percentage of filled teeth (FT) and decayed teeth (DT) according to the DMFT index was $2 \%$ and $77 \%$, respectively. The mean DT, missing teeth (MT) and FT index scores were $0.52 \pm 0.60,0.00 \pm 0.02$ and $0.00 \pm 0.01$, respectively. The difference in the DMFT index score for the different age groups and regions was statistically significant $(\mathrm{p}=<0.001$ and $\mathrm{p}=0.036$, respectively) (Figure $1 \& 2$ ). The overall prevalence of dental caries, plaque and gingival bleeding in the different age groups and regions is summarised in Table 3. 


\section{Advances in Dentistry \& Oral Health}

Table 3: The overall prevalence of dental caries, plaque and gingival bleeding in the different age groups and school regions.

\begin{tabular}{|c|c|c|c|c|c|c|c|c|c|c|c|c|c|}
\hline \multirow{2}{*}{ Variable } & \multirow{2}{*}{$\mathbf{n}$} & \multirow{2}{*}{$\begin{array}{c}\% \\
\text { Caries }\end{array}$} & \multicolumn{3}{|c|}{ DMFT } & \multirow{2}{*}{$\begin{array}{c}\% \\
\text { Plaque }\end{array}$} & \multicolumn{3}{|c|}{ PI } & \multirow{2}{*}{$\begin{array}{c}\% \\
\text { Gingival } \\
\text { Bleeding }\end{array}$} & \multicolumn{3}{|c|}{ GI } \\
\hline & & & Mean & Median & p-value* & & Mean & Median & p-value* & & Mean & Median & p-value* \\
\hline \multicolumn{14}{|l|}{ Age (years) } \\
\hline $12-13$ & 110 & 85.5 & $0.86 \pm 0.62$ & 1.14 & \multirow{3}{*}{$<0.001$} & 94.5 & $1.30 \pm 0.63$ & 1.33 & & 85.5 & $1.00 \pm 0.98$ & 1 & \multirow{3}{*}{0.058} \\
\hline 14 & 75 & 68 & $0.21 \pm 0.38$ & 0.07 & & 90.7 & $1.37 \pm 0.67$ & 1.33 & 0.004 & 86.7 & $1.05 \pm 0.84$ & 1 & \\
\hline 15 & 64 & 68.7 & $0.10 \pm 0.11$ & 0.07 & & 98.4 & $1.62 \pm 0.68$ & 1.67 & & 87.5 & $1.23 \pm 0.80$ & 1.33 & \\
\hline \multicolumn{14}{|c|}{ School location } \\
\hline Alaquiq & 125 & 78.4 & $0.49 \pm 0.62$ & 0.14 & \multirow{4}{*}{0.036} & 94.4 & $1.40 \pm 0.66$ & 1.5 & & 88 & $1.26 \pm 1.02$ & 1.17 & \multirow{4}{*}{0.003} \\
\hline Alatawelah & 68 & 72.1 & $0.33 \pm 0.48$ & 0.07 & & 95.6 & $1.55 \pm 0.67$ & 1.67 & 0.025 & 85.3 & $1.01 \pm 0.76$ & 1 & \\
\hline Albaha & 56 & 75 & $0.60 \pm 0.57$ & 0.32 & & 92.9 & $1.23 \pm 0.64$ & 1.33 & & 83.9 & $0.75 \pm 0.64$ & 0.5 & \\
\hline $\begin{array}{c}\text { Overall } \\
\text { prevalence }\end{array}$ & 249 & 76 & $0.47 \pm 0.58$ & 0.14 & & 94.4 & $1.40 \pm 0.67$ & 1.5 & & 86.3 & $1.08 \pm 0.90$ & 1 & \\
\hline
\end{tabular}

*: The p-values were calculated using the median

\section{Plaque and gingival bleeding}

The prevalence of plaque and gingival bleeding was significantly high in the current study, affecting 235 (94\%) and 215 cases (86\%), respectively. Although the PI and GI values violated the normality assumption, the mean PI and GI value was $1.40 \pm$ 0.67 and $1.08 \pm 0.90$, respectively. The difference in the GI scores for the different regions was found to have statistical significance $(p=0.003)$. However, this was not the case with respect to the difference in GI scores for the different age groups ( $p=0.058$ ). By contrast, statistical significance was attributed to the difference in PI values for the participants in the different regions and age groups ( $\mathrm{p}=0.025$ and $\mathrm{p}=0.004$, respectively) (Figure $1 \& 2$ ).

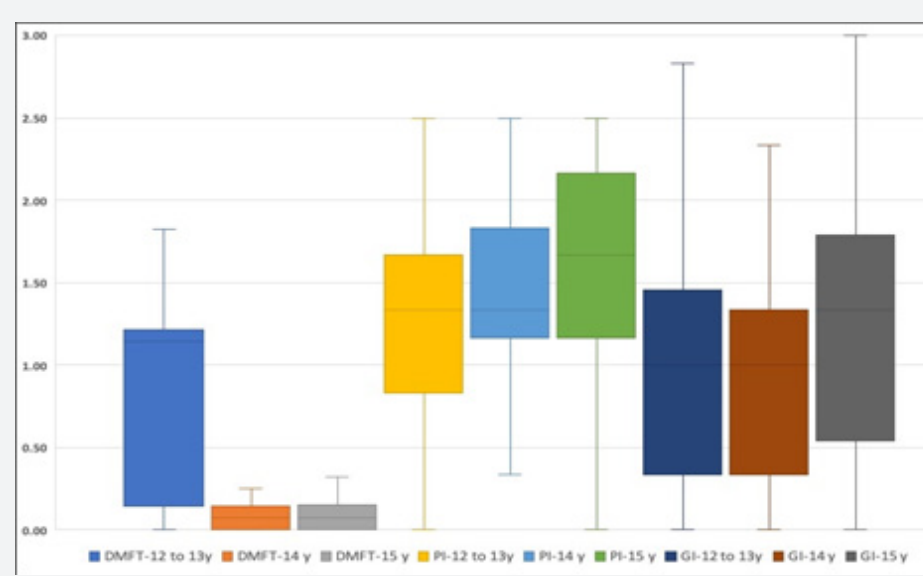

Figure 1. A comparison of medians for the DMFT, PI, and GI Indices among different age groups.

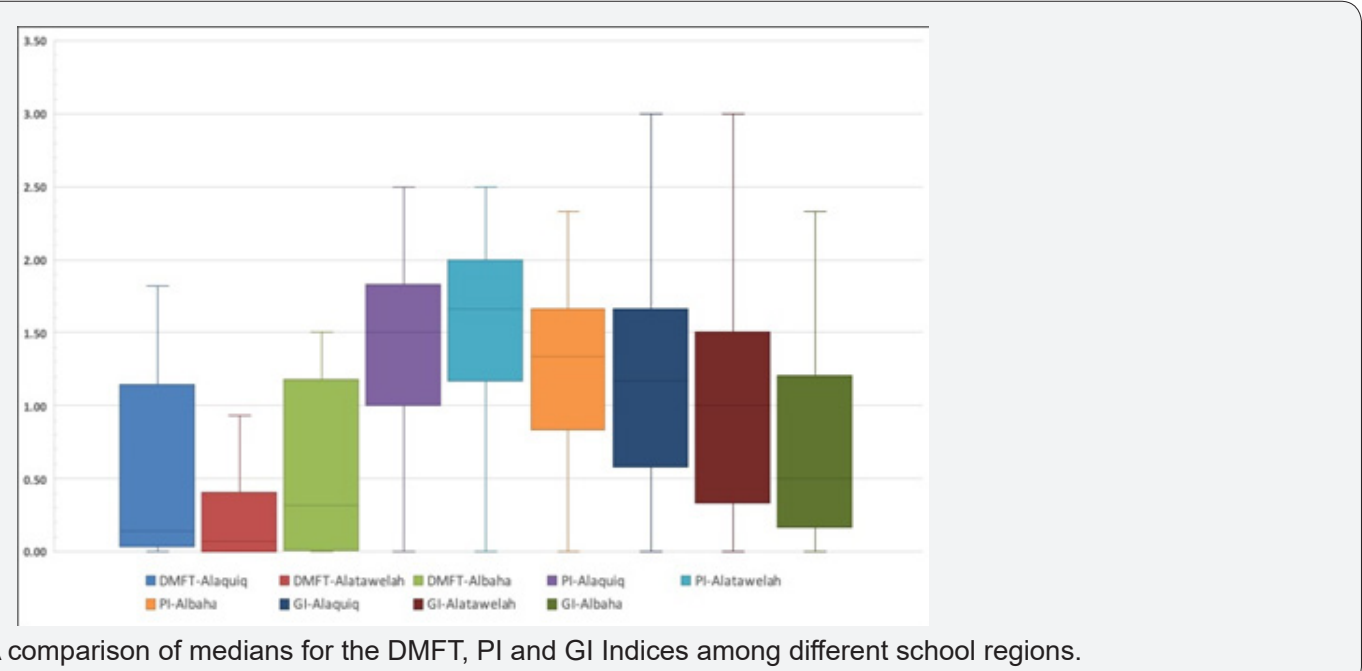

Figure 2. A comparison of medians for the DMFT, PI and GI Indices among different school regions. 


\section{Attitudes to the preservation of oral health}

Three quarters of the adolescents ( $n=186,73 \%$ ) were seen to hold a moderate attitude towards the preservation of their oral health. The approach to oral health was found to be poor for 61 of the study participants (25\%) and sound for only six of them (2\%). The identified differences in attitudes to oral health among the different age groups and regions (schools) was without statistical significance.

Surprisingly, 43\% ( $n=106)$ of the participants had not visited the dentist and only $16 \%(n=39)$ reported brushing their teeth twice daily. A third of the sample $(n=89,36 \%)$ preferred to clean their teeth using a toothbrush and toothpaste rather than miswak, an herbal chewing stick. Only $9 \%$ and $14 \%$ of the participants regularly used dental floss and mouthwash, respectively. Nevertheless, most of them admitted to being concerned about the color and appearance of their teeth and gums (81\% and $77 \%$, respectively). The attitudes of the study participants to their oral health are detailed in Table 4.

The association between the pooled scores for attitudes to oral health and the DMFT index and the GI index was not found to be statistically significant $(\mathrm{p}=0.741$ and $\mathrm{p}=0.352$, respectively). Interestingly, statistical significance was reported for the association between the pooled scores for attitudes to oral health and the PI $(p=0.023)$. Several of the attitudes to oral health were shown to have a statistically significant association with the DMFT index, PI and GI on bivariate analysis. The correlation between activities such as visiting the dentist, using mouthwash, being concerned about bad breath, going for regular dental checkups (even in the absence of toothache or complications) and using dye to identify plaque on the teeth and the DMFT index score was statistically significant $(\mathrm{p}=0.001,0.048,0.01,0.003$ and 0.006 , respectively). Likewise, the correlation between attitudes towards and factors linked to the preservation of oral health, such as visiting the dentist, brushing the teeth carefully, the absence of bleeding gums during brushing, and going for regular dental check-ups (even in the absence of toothache or complications) and the PI and GI scores was statistically significant. The findings of the bivariate analysis of the association between attitudes to oral health and the DMFT index scores, and PI and GI scores are detailed in Table 4.

Table 4: Bivariate analysis of the association between attitudes to oral health and the decayed, missing or filled Teeth (DMFT) index, plaque index $(\mathrm{PI})$ and gingival bleeding $(\mathrm{Gl})$ index scores $(n=249)$.

\begin{tabular}{|c|c|c|c|c|c|c|c|}
\hline \multirow{2}{*}{ Description of attitudes to oral health } & \multirow{2}{*}{$\begin{array}{c}\text { Agree n } \\
\text { (\%) }\end{array}$} & \multicolumn{2}{|c|}{ DMFT } & \multicolumn{2}{|c|}{ Plaque Index } & \multicolumn{2}{|c|}{ Gingival Index } \\
\hline & & Chi-square & p-value & Chi-square & p-value & Chi-square & p-value \\
\hline $\begin{array}{l}\text { I have visited my dentist and was informed } \\
\text { that I brush my teeth very well. }\end{array}$ & $143(57)$ & 10.74 & 0.001 & 3.597 & 0.058 & 5.808 & 0.016 \\
\hline $\begin{array}{l}\text { I brush my teeth twice daily and have been } \\
\text { taught how to use my brush professionally. }\end{array}$ & $39(16)$ & 0.033 & 0.856 & 2.852 & 0.091 & 7.432 & 0.006 \\
\hline I brush each one of my teeth carefully. & $89(36)$ & 1.025 & 0.311 & 11.047 & 0.001 & 5.602 & 0.018 \\
\hline $\begin{array}{l}\text { I prefer to clean my teeth using a toothbrush } \\
\text { and toothpaste rather than miswak. }\end{array}$ & $89(36)$ & 0.233 & 0.629 & 0.15 & 0.698 & 0.575 & 0.448 \\
\hline $\begin{array}{l}\text { I use a child-sized toothbrush with hard } \\
\text { bristles. }\end{array}$ & $99(40)$ & 1.122 & 0.29 & 4.444 & 0.035 & 2.779 & 0.095 \\
\hline $\begin{array}{l}\text { I often check my teeth in the mirror after } \\
\text { brushing them. }\end{array}$ & $182(73)$ & 0.005 & 0.943 & 0.004 & 0.951 & 1.354 & 0.245 \\
\hline $\begin{array}{l}\text { I don't feel I have brushed my teeth well unless } \\
\text { I use strong strokes. }\end{array}$ & $119(48)$ & 0.024 & 0.878 & 3.578 & 0.059 & 3.926 & 0.048 \\
\hline I use floss on a regular basis. & $22(9)$ & 0.406 & 0.524 & 0.313 & 0.576 & 0.29 & 0.59 \\
\hline $\begin{array}{l}\text { I am worried about the color and appearance } \\
\text { of my teeth. }\end{array}$ & 201 (81) & 0.525 & 0.469 & 1.172 & 0.279 & 1.739 & 0.187 \\
\hline $\begin{array}{l}\text { I am concerned about the color and } \\
\text { appearance of my gums. }\end{array}$ & 192 (77) & 0.815 & 0.367 & 5.218 & 0.022 & 2.162 & 0.141 \\
\hline My gums do not bleed when I brush my teeth. & $83(33)$ & 0.008 & 0.928 & 12.912 & $<0.000$ & 11.302 & 0.001 \\
\hline I regularly use mouthwash. & $35(14)$ & 3.908 & 0.048 & 0.012 & 0.911 & 0.052 & 0.819 \\
\hline I worry about having bad breath. & $208(84)$ & 6.712 & 0.01 & 4.367 & 0.037 & 2.042 & 0.153 \\
\hline $\begin{array}{l}\text { Generally, I try to visit the dentist regularly, } \\
\text { even if I don't have toothache. }\end{array}$ & $100(40)$ & 8.695 & 0.003 & 5.951 & 0.015 & 10.282 & 0.001 \\
\hline $\begin{array}{l}\text { I have used dye to determine to what extent } \\
\text { my teeth are clean. }\end{array}$ & $88(35)$ & 7.474 & 0.006 & 1.128 & 0.288 & 1.019 & 0.313 \\
\hline
\end{tabular}




\section{Discussion}

Dental epidemiology is performed to evaluate the oral health needs of a community to assist with the planning, assessment, implementation and auditing of preventive strategies and/or oral healthcare programmes to reduce the prevalence of dental disease $[20,21]$. However, there is a lack of studies in the dental literature on the oral health status and attitudes of schoolchildren in Albaha province, Saudi Arabia, and particularly those of adolescents aged 12-15 years. This is reflective of the significance of conducting a cross-sectional study in this regard, especially since dental disease is a public health problem globally [21], and such a study has not yet been published.

The overall incidence of dental caries, plaque and gingival bleeding in the studied population was found to be significantly high in the current study, consistent with the findings of previous research conducted in Saudi Arabia across several cities, including Dammam, Tabuk, Riyadh and Jeddah [5-8,10-12]. This might indicate that dental caries and periodontal disease in Saudi Arabia are not treated regularly, similar to conditions in several developing countries [22,23]. Nonetheless, there might be an essential need to develop focused oral disease prevention and health-promoting strategies, such as promoting the application of pit and fissure sealant and/or establishing oral health education school programmes across these communities [24,25].

The oral health status of Saudi children in Albaha province was shown to be relatively poor in the current study, with a statistically significant variation in the DMFT index, GI and PI values among the children in the different school regions. These findings might indicate that the unequal distribution of dental services and/ or challenges with accessibility and transportation to existing dental services in the Albaha region could be possible reasons for the variation in the DMFT index, PI and GI values [26]. Further research is warranted to explore this area in depth and validate the study findings in order to ensure that similar treatment protocols are applied across the different territories.

Interestingly, although the prevalence of dental caries, plaque and gingival bleeding was high in the current study, moderate attitudes to oral health were attributed to most of the study subjects (73\%). These findings are like those of previous research carried out on Saudi children [27]. This may suggest the need for the implementation of a combination of several oral health-related educational and practice programmes at schools, in addition to a follow-up of the progress of and effort made by children to improve their oral health status [28,29].

It was demonstrated in the current study that roughly half of the participants $(40 \%)$ believed in the importance of attending dental check-ups regularly, even in the absence of toothache or complications, but only $16 \%$ of them brushed their teeth twice daily and had been taught how to do it properly. Yet, evidence has shown that the oral health practices of parents' influence their children's dental status [30]. Potentially, this may signify that there is a crucial need to motivate parents and schoolchildren to adhere to sound oral health practices and lifestyles, particularly about controlling sugar consumption prior to and at bedtime, and using fluoride toothpaste [30,31].

There were limitations to the study. Female adolescents were not included in the study sample, mainly owing to cultural challenges in accessing this population at school, particularly as the researchers were men, thus impeding the ability to generalize the study findings. Even though this was a cross-sectional survey and that it involved a limited sample size, it nevertheless offers insight into the oral health status and attitudes of Saudi adolescent male students in Albaha province. A further limitation was the potential inhibition of the ability to evaluate the causal relationships between the study variables owing to the cross-sectional design. For instance, it was difficult to definitively claim that the high prevalence of dental caries was caused by poor attitudes to oral health. However, the study focus was to examine and explore the oral health conditions and attitudes of adolescents, rather than to measure causal associations.

\section{Conclusion}

A high prevalence of dental caries, plaque and gingival bleeding was identified in Saudi adolescent male students aged 12-15 years in Albaha province, following an exploration of their attitudes to oral health and an evaluation of their oral health status via a clinical examination. Nevertheless, most of the participants were observed to have moderate attitudes to their oral health. This may highlight the need for the implementation of oral health promotional and educational programs, in conjunction with the development of suitable oral health preventive strategies to ensure the restriction of sugar consumption, the use of fluoride toothpaste and the application of pit and fissure sealant. Future research may also be warranted into discrepancies in the distribution of dental services throughout the country and/or accessibility to existing dental services in Albaha province.

\section{Acknowledgement}

The Deanship of Scientific Research at Albaha University, Saudi Arabia, is acknowledged for funding this research (reference number 68/1438) in the $2017 / 2018$ academic year.

\section{Conflict of Interest}

All authors declare that there was no conflict of interest regarding the authorship and/or publication of this study.

\section{References}

1. Martins-Junior PA, Vieira-Andrade RG, Correa-Faria P, Oliveira-Ferreira F, Marques LS, et al. (2013) Impact of early childhood caries on the oral health-related quality of life of preschool children and their parents. Caries Res 47(3): 211-218.

2. Henrik J, Åsa W, Veronica J, Sigvard $\AA$, Nina L, et al. (2014) Impact of Periodontal Disease Experience on Oral Health-Related Quality of Life. J Periodontol 85(3): 438-445.

3. Khan SQ Khan NB, ArRejaie AS (2013) Dental Caries: A meta-analysis on a Saudi population. Saudi Med J 34(7): 744-749. 


\section{Advances in Dentistry \& Oral Health}

4. Al Agili DE (2013) A systematic review of population-based dental caries studies among children in Saudi Arabia. The Saudi Dental Journal 25(1): 3-11.

5. Farooqi FA, Khabeer A, Moheet IA, Khan SQ, Farooq I (2015) Prevalence of dental caries in primary and permanent teeth and its relation with tooth brushing habits among schoolchildren in Eastern Saudi Arabia. Saudi Med J 36(6): 737-742.

6. Baghdadi ZD (2014) Improving oral health status of children in Tabuk, Saudi Arabia. Dentistry Journal 2(1): 22-40.

7. Alamri A, Aldossary M, Alshiha S, Alwayli H, Alfraih Y, et al. (2017) Dental caries prevalence among primary male schoolchildren in Riyadh, Saudi Arabia: A cross-sectional survey. Journal of International Oral Health 9(4): 146-150.

8. Farsi DJ, Elkhodary HM, Merdad LA, Farsi NM, Alaki SM, et al. (2016) Prevalence of obesity in elementary school children and its association with dental caries. Saudi Med J 37(12): 1387-1394.

9. Keller A, Rohde JF, Raymond K, Heitmann BL (2015) Association between periodontal disease and overweight and obesity: a systematic review. J Periodontol 86(6): 766-776.

10. AlSarheed MA (2015) Comparative study of oral health among trisomy 21 children living in Riyadh, Saudi Arabia: Part 2, gingival condition The Saudi Dental Journal 27(4): 224-227.

11. Quadri M, Shubayr M, Hattan A, Wafi S, Jafer A (2018) Oral Hygiene Practices among Saudi Arabian Children and Its Relation to Their Dental Caries Status. International Journal of Dentistry 2018: 1-6.

12. Idrees MM, Azzeghaiby SN, Hammad MM, Kujan OB (2014) Prevalence and severity of plaque-induced gingivitis in a Saudi adult population. Saudi Med J 35(11): 1373-1377.

13. Sabbah W, Tsakos G, Chandola T, Sheiham A, Watt RG (2007) Social Gradients in Oral and General Health. J Dent Res 86(10): 992-996.

14. Puy CL (2006) The role of saliva in maintaining oral health and as an aid to diagnosis. Med Oral Patol Oral Cir Bucal 11(5): 449-455.

15. Al Subait AA, Alousaimi M, Geeverghese A, Ali A, El Metwally A (2016) Oral health knowledge, attitude and behavior among students of age 10-18 years old attending Jenadriyah festival Riyadh; a cross-sectional study. The Saudi Journal for Dental Research 7(1): 45-50.

16. Togoo RA, Yaseen SM, Zakirulla M, Nasim V, Al Zamzami M (2012) Oral hygiene knowledge and practices among school children in a rural area of southern Saudi Arabia. International Journal of Contemporary Dentistry 3(1).

17. Barbosa T, Gavião M (2008) Oral health-related quality of life in children: part II. Effects of clinical oral health status. A systematic review. International Journal of Dental Hygiene 6(2): 100-107.
18. The World Health Organization (2013) Oral Health Surveys: Basic Methods. World Health Organization, Geneva, Switzerland.

19. Komabayashi T, Kawamura M, Kim KJ, Wright FA, Declerck D, et al. (2006) The hierarchical cluster analysis of oral health attitudes and behaviour using the Hiroshima University--Dental Behavioural Inventory (HU-DBI) among final year dental students in 17 countries. International Dental Journal 56(5): 310-316.

20. Pearce N (2012) Classification of epidemiological study designs. Int J Epidemiol 41(2): 393-397.

21. Veiga N, Coelho I (2015) The Importance of Epidemiology in Dental Medicine. Journal of Dental and Oral Health 41: 983-1984.

22. Petersen PE (2014) Strengthening of oral health systems: oral health through primary health care. Medical Principles and Practice 23 Suppl 1: 13-19.

23. Jurgensen N, Petersen PE (2009) Oral health and the impact of sociobehavioural factors in a cross-sectional survey of 12 -year old school children in Laos. BMC Oral Health 2009(9): 929-939.

24. Papageorgiou SN, Dimitraki D, Kotsanos N, Bekes K, van Waes H (2017) Performance of pit and fissure sealants according to tooth characteristics: A systematic review and meta-analysis. Journal of Dentistry 66: 8-17.

25. Nakre PD, Harikiran AG (2013) Effectiveness of oral health education programs: A systematic review. Journal of International Society of Preventive \& Community Dentistry 3(2): 103-115.

26. Reda SF, Reda SM, Thomson WM, Schwendicke F (2018) Inequality in Utilization of Dental Services: A Systematic Review and Meta-analysis. American journal of public health 108(2): 1-7.

27. Farsi JM, Farghaly MM, Farsi N (2004) Oral health knowledge, attitude and behaviour among Saudi school students in Jeddah city. Journal of Dentistry 32(1): 47-53.

28. Hazavehei SMM, Shirahmadi S, Taheri M, Noghan N, Rezaei N (2015) Promoting Oral Health in 6-12-Year-Old Students: A Systematic Review. Journal of Education and Community Health 1(4): 66-84.

29. Rad M, Shahravan A, Haghdoost AA (2015) A systematic review of questionnaires used on oral health knowledge, attitude, land practice in 12-year-olds. Journal of Oral Health and Epidemiology 5(1): 1-12.

30. Castilho AR, Mialhe FL, Barbosa T de S, Puppin-Rontani RM (2013) Influence of family environment on children's oral health: a systematic review. J Pediatr (Rio J) 89(2): 116-123.

31. Baghlaf K, Muirhead V, Moynihan P, Weston-Price S, Pine C (2018) Free Sugars Consumption around Bedtime and Dental Caries in Children: A Systematic Review. JDR Clinical \& Translational Research 3(2): 118129.

\section{Your next submission with Juniper Publishers} will reach you the below assets

- Quality Editorial service

- Swift Peer Review

- Reprints availability

- E-prints Service

- Manuscript Podcast for convenient understanding

- Global attainment for your research

- Manuscript accessibility in different formats

(Pdf, E-pub, Full Text, Audio)

- Unceasing customer service

Track the below URL for one-step submission

https://juniperpublishers.com/online-submission.php 